\title{
(a) OPEN ACCESS \\ Resuscitation of preterm infants in the Philippines: a national survey of resources and practice
}

\author{
Dean Hayden (D) , ${ }^{1,2}$ Maria Esterlita Villanueva-Uy, ${ }^{3}$ Maria Katrina Mendoza, ${ }^{4}$ \\ Dominic Wilkinson ${ }^{1,5}$
}

\begin{abstract}
- Additional material is published online only. To view please visit the journal online (http://dx.doi.org/10.1136/ archdischild-2019-316951).

'Oxford Uehiro Centre for Practical Ethics, University of Oxford, Oxford, UK ${ }^{2}$ Faculty of Medicine, Nursing and Health Sciences, Monash University, Melbourne, Australia ${ }^{3}$ Institute of Child Health and Human Development, National Institute of Health, Manila, Philippines

${ }^{4}$ Kangaroo Mother Care Foundation, Manila, Philippines 5John Radcliffe Hospital, Oxford, UK
\end{abstract}

\section{Correspondence to}

Dr. Dominic Wilkinson, Oxford Uehiro Centre for Practical Ethics, University of Oxford, Oxford OX1 2JD, UK;

dominic.wilkinson@philosophy. ox.ac.uk

Received 31 January 2019 Revised 25 May 2019

Accepted 31 May 2019 Published Online First 14 June 2019
ABSTRACT

Objective There is a high incidence of preterm birth in low-income and middle-income countries where healthcare resources are often limited and may influence decision making. We aimed to explore the interplay between resource limitations and resuscitation practices for extremely preterm infants (EPIs) in neonatal intensive care units (NICUs) across the Philippines.

Methods We conducted a national survey of NICUs in the Philippines. Institutions were classified according to sector (private/public), region and level. Respondents were asked about unit capacity, availability of ventilators and surfactant, resuscitation practices and estimated survival rates for EPIs of different gestational ages.

Results Respondents from 103/228 hospitals completed the survey (response rate $45 \%$ ). Public hospitals reported more commonly experiencing shortages of ventilators than private hospitals ( $85 \%$ vs $23 \%$, p < 0.001 ). Surfactant was more likely to be available in city hospitals than regional/district hospitals $(p<0.05)$ and in hospitals classified as Level III/IV than I/II $(p<0.05)$. The financial capacity of parents was a major factor influencing treatment options. Survival rates for EPIs were estimated to be higher in private than public institutions. Resuscitation practice varied; active treatment was generally considered optional for EPIs from 25 weeks' gestation and usually provided after 27-28 weeks' gestation.

Conclusion Our survey revealed considerable disparities in NICU resource availability between different types of hospitals in the Philippines. Variation was observed between hospitals as to when resuscitation would be provided for EPIs. National guidelines may generate greater consistency of care yet would need to reflect the variable context for decisions in the Philippines.

\section{INTRODUCTION}

In many countries, professional organisations have developed guidelines for the perinatal care of extremely preterm infants (EPIs), including when resuscitation should or should not be provided. Most existing guidelines indicate thresholds based on the infant's gestational age (GA). ${ }^{1}{ }^{2}$ A lower threshold marks the gestation before which treatment will not usually be provided. An upper threshold marks the point after which treatment is considered mandatory. Between these ages lies a 'grey zone', where active treatment may or may not be provided, and parents' wishes are important.

Published guidelines stem from high-income countries or international bodies. ${ }^{3-5}$ However,

\section{What is already known on this topic?}

- Many professional organisations and societies have developed management guidelines to support clinicians facing decisions about offering or withholding resuscitation for extremely preterm infants. There are no available guidelines that provide specific advice to clinicians in low-income or middle-income country while incorporating considerations of resource constraints. Studies from these settings have shown significant variation in resuscitation practices between and within countries.

\section{What this study adds?}

- This is the first study to assess both availability of neonatal intensive care unit resources and resuscitation practices of preterm infants across an entire low-income or middle-income country.

the vast majority of preterm births globally occur in low-income and middle-income countries (LMICs), where resource limits can affect the provision of medical care. ${ }^{6-10}$ To our knowledge, there are no published national guidelines for clinicians resuscitating preterm infants in these settings. Several studies have examined practice in individual hospitals or regions in LMICs, indicating variation between and within countries in the GA and birth weight thresholds used for resuscitation. ${ }^{11-18}$

The aim of this study was to survey neonatologists across an LMIC about resuscitation decisions for EPIs. We aimed to assess whether resuscitation practices varied between sectors of the health system and to identify the influence of resource limitations.

The Philippines is an archipelagic country with a population of 105 million and a gross domestic product (GDP)/capita of US\$2989. ${ }^{19}$ Worldwide, it ranks eighth highest in number of preterm births (350 000/year). ${ }^{6} 20$ The average neonatal mortality rate is estimated to be 14 per 1000 live births, though there is wide regional variation (it is lower in urban areas but $>20 / 1000$ live births in some provinces). ${ }^{21} 22$ As in many other LMICs, for both private and public facilities, parents are required to pay out of pocket for the care of their infant. $^{23}$ 


\section{METHODS}

\section{Participants}

Neonatologists working in neonatal intensive care units (NICU) in the Philippines were contacted through a database provided by the Philippine Pediatric Society. For each hospital, a single neonatologist was identified to respond on their institution's behalf. In some cases, one clinician was asked to complete the survey more than once, on behalf of multiple hospitals, as they were the only neonatologists working at those institutions. Up to three reminder emails and a single text message were sent to non-responders.

\section{Evaluation instrument}

A 34-item SurveyMonkey questionnaire was developed. The survey was written and conducted in English, an official language of the Philippines. ${ }^{24} 25$ Participation was voluntary, and responses were anonymous. The survey was conducted between January and March 2018.

The survey was structured in three main parts. The first requested information on the characteristics of the hospital including numbers of overall and preterm births. The second focused on availability of resources including number of beds, mechanical ventilators and surfactant. The third requested information about hospital policies and practice relating to resuscitation of EPIs. Respondents were asked how often resuscitation would be provided for infants born at a given gestation.

Questions consisted of Likert scale responses, yes/no, multiple choices and open-ended questions. For questions asking the frequencies of particular occurrences, 'never' and 'rarely' responses were grouped into a single category, as were 'often' and 'almost always' in our analysis. Clinicians were also asked about factors influencing decision making. ${ }^{14}$

Lastly, the survey asked for sociodemographic information from respondents including level of experience, religion and level of religiosity.

\section{Statistical analysis}

Data were analysed using the Statistical Package for Social Sciences (SPSS) v25.0. ${ }^{26}$ Bivariate analyses to assess association between categorical outcomes were performed using Fisher's exact test. Mann-Whitney $U$ and Kruskal-Wallis tests were used for assessing differences between continuous variables. We analysed separately survival estimates for Level III/IV hospitals, as these would have most experience of caring for EPIs.

We assessed the frequency by which each institution would initiate resuscitation for infants of a given GA. We performed a post hoc analysis using Fisher's exact test to assess if responses differed between different types of institutions at either 23/24 weeks' gestation or $27 / 28$ weeks' gestation.

\section{RESULTS}

\section{Participants}

Of the 228 hospitals providing neonatal care in the Philippines, we received 103 responses, yielding an overall response rate of $45 \%$. Responses were submitted by 83 different neonatologists (14 entered data for more than one hospital). Most responses were from city hospitals, and approximately two-thirds were from private hospitals (table 1$)$. The majority of respondents $(75 \%)$ had more than 10 years' experience of working in NICU.

\section{Births and resource availability}

Respondents from higher level hospitals reported a larger number of beds and ventilators (online supplementary appendix 1). Compared
Table 1 Hospital and respondent characteristics

No. $(\%)$

\begin{tabular}{|c|c|}
\hline \multicolumn{2}{|l|}{ Hospital classification $(n=103)$} \\
\hline \multicolumn{2}{|l|}{ Administrative sector } \\
\hline Public/government & $34(33)$ \\
\hline Private & $69(67)$ \\
\hline \multicolumn{2}{|l|}{ Region* } \\
\hline City & $81(79)$ \\
\hline Provincial & $17(16)$ \\
\hline District & $5(5)$ \\
\hline \multicolumn{2}{|l|}{ Levelt } \\
\hline Level I & $6(6)$ \\
\hline Level II & $28(27)$ \\
\hline Level III & $56(54)$ \\
\hline Level IV & $10(10)$ \\
\hline Unknown/unclassified & $3(3)$ \\
\hline \multicolumn{2}{|l|}{ Respondent characteristics $(n=83)$} \\
\hline \multicolumn{2}{|l|}{ Professional role } \\
\hline Consultant & $81(98)$ \\
\hline Registrar/fellow & $2(2)$ \\
\hline \multicolumn{2}{|l|}{ Gender } \\
\hline Male & $21(25)$ \\
\hline Female & $62(75)$ \\
\hline \multicolumn{2}{|l|}{ Years working in NICU } \\
\hline $1-5$ years & $12(15)$ \\
\hline $6-10$ years & $8(10)$ \\
\hline $11-15$ years & $14(17)$ \\
\hline $16-20$ years & $27(33)$ \\
\hline$>20$ years & $20(24)$ \\
\hline \multicolumn{2}{|l|}{ Religious belief } \\
\hline Yes & $83(100)$ \\
\hline Atheist/agnostic & 0 \\
\hline \multicolumn{2}{|l|}{ Religious denomination§ } \\
\hline Christianity - Catholic & $68(82)$ \\
\hline Christianity - Evangelical & $6(7)$ \\
\hline Christianity - Born Again Christians & $6(7)$ \\
\hline Christianity - Baptist & $2(2)$ \\
\hline Prefer not to say & $1(1)$ \\
\hline \multicolumn{2}{|l|}{ Importance of religion§ } \\
\hline Most important & $31(37)$ \\
\hline Very important & $50(60)$ \\
\hline Fairly important & $2(2)$ \\
\hline Not important & 0 \\
\hline
\end{tabular}

*Hospitals in the Philippines fall under different regional administrative units; city hospitals (managed by city governments), 'district' and 'provincial' hospitals (both managed by the provincial government and the latter providing tertiary care to a greater catchment area). ${ }^{23}$

thospitals are classified into four different levels according to the types of facilities available. Level 1 and 2 hospitals are well distributed across the entire country, while higher level hospitals are concentrated in fewer regions with greater population density. ${ }^{33}$

‡Numbers sum up to 81 as two respondents did not answer this question. $\S$ For respondents who indicated that they had a religion. Refers to importance of religion in respondents' lives.

$\mathrm{NICU}$, neonatal intensive care unit.

with private hospitals, public hospitals reported a significantly higher number of births and preterm births, a larger number of beds but a lower number of ventilators per 100 preterm births.

Most hospitals reported experiences of limitations in available ventilators at least some of the time (table 2). While 32\% 
Table 2 Frequency of resource limitations in newborn intensive care: mechanical ventilation and surfactant administration

\begin{tabular}{|c|c|c|c|c|c|c|c|c|c|c|}
\hline & \multicolumn{2}{|l|}{ Level } & \multirow[b]{2}{*}{ P value* } & \multicolumn{2}{|c|}{ Administration } & \multirow[b]{2}{*}{ P value* } & \multicolumn{3}{|l|}{ Region } & \multirow[b]{2}{*}{ P value* } \\
\hline & I/II & III/IV & & Public & Private & & City & Provincial & District & \\
\hline \multicolumn{11}{|c|}{ Frequency of situations where all mechanical ventilators are in use and at least one other infant needs mechanical ventilationt } \\
\hline Never/rarely & $5(15)$ & $17(26)$ & 0.04 & $2(6)$ & $21(30)$ & $<0.001$ & $22(28)$ & $1(5.9)$ & 0 & 0.003 \\
\hline Some of the time & $15(44)$ & $13(20)$ & & $3(9)$ & $26(38)$ & & $26(33)$ & $1(5.9)$ & $2(40)$ & \\
\hline Often/almost always & $14(41)$ & $35(54)$ & & $28(85)$ & $22(32)$ & & $32(40)$ & $15(88.2)$ & $3(60)$ & \\
\hline \multicolumn{11}{|c|}{ Availability of surfactant for preterm infants with respiratory distress $t$} \\
\hline Never & $3(9)$ & $5(8)$ & 0.02 & $6(19)$ & $2(3)$ & 0.06 & $3(4)$ & $4(27)$ & $1(20)$ & 0.02 \\
\hline Some of the time & $6(18)$ & $6(10)$ & & $3(10)$ & $10(15)$ & & $12(15)$ & $1(7)$ & 0 & \\
\hline Only if parents are able to pay & $19(56)$ & $21(34)$ & & $13(42)$ & $29(43)$ & & $32(41)$ & $6(40.0)$ & $4(80)$ & \\
\hline Always & $6(18)$ & $30(48)$ & & $9(29)$ & $27(40)$ & & $32(41)$ & $4(27)$ & 0 & \\
\hline
\end{tabular}

*Fisher's exact test. $P$ values represent differences in overall distribution of responses between different hospitals types.

tRarely=less than once per year, some of the time=more than once per year but less than once per month, often=more than once per month but less than once per week and almost always=more than once per week.

‡This option included situations where the parents are able to find a charity to cover the costs of care.

of private hospitals reported being 'often' or 'always' at full capacity for ventilators, this was reported by $85 \%$ of public hospitals $(\mathrm{p}<0.001)$.

Forty-one per cent of hospitals reported that surfactant for respiratory distress syndrome was available only if parents or a charity were able to pay for it. Surfactant was more likely to be 'always' available in higher level hospitals $(\mathrm{p}<0.05)$ and more often available in city hospitals than provincial/district hospitals $(\mathrm{p}<0.05)$.

The most common responses to ventilator shortages were for the family to rent a ventilator, to attempt hand-ventilation, or to transfer the infant to another facility (table 3). Most hospitals reported no specific limitations on which preterm infants receive

\begin{tabular}{|c|c|}
\hline & No. $(\%)^{*}$ \\
\hline \multicolumn{2}{|l|}{$\begin{array}{l}\text { Course of action if all ventilators are in use and another infant requires } \\
\text { mechanical ventilation }(n=92)\end{array}$} \\
\hline The family will hire a ventilator from a rental company & $52(57)$ \\
\hline Hand ventilation is attempted if there are individuals able to do so & $40(44)$ \\
\hline The neonate is transferred to a facility with an available ventilator & $37(40)$ \\
\hline $\begin{array}{l}\text { Babies who are currently on the ventilator and who are on low } \\
\text { ventilation settings are taken off support in the hope that they won't } \\
\text { need it }\end{array}$ & $12(13)$ \\
\hline $\begin{array}{l}\text { The hospital will hire a ventilator from a third party or source one } \\
\text { from another unit }\end{array}$ & $12(13)$ \\
\hline CPAP is attempted (either nasal or ET) & $4(4)$ \\
\hline New babies who need treatment are kept comfortable and die & $1(1)$ \\
\hline \multicolumn{2}{|c|}{$\begin{array}{l}\text { Rules or limitations placed on which infants are able to receive surfactant: } \\
(n=65)\end{array}$} \\
\hline No rules or limitations placed & $29(45)$ \\
\hline Financial capacity of family & $23(35)$ \\
\hline The infant must fall within a particular GA range & $6(9)$ \\
\hline There is a maximum number of doses due to cost & $4(6)$ \\
\hline Availability of medication & $4(6)$ \\
\hline Availability of a mechanical ventilator & $1(2)$ \\
\hline The infant must be of a minimum birth weight & $1(2)$ \\
\hline \multicolumn{2}{|c|}{$\begin{array}{l}\text { *Respondents could select more than one answer. Percentages reflect the } \\
\text { proportion of respondents who selected a particular answer, therefore percentages } \\
\text { do not total } 100 \text {. } \\
\text { CPAP, continuous positive airway pressure; ET, endotracheal tube; GA, gestational } \\
\text { age. }\end{array}$} \\
\hline
\end{tabular}

surfactant. Of the hospitals that did report a limiting factor, most cited the family's financial capacity.

\section{Costs of care}

The median reported costs to parents for different services are shown in online supplementary appendix 2 . The costs of daily NICU care, ventilator rental and surfactant administration were significantly higher in private hospitals.

\section{Survival rates}

The estimated rate of survival for preterm infants increased with GA (figure 1), though there was wide variation in the estimates. Respondents consistently estimated higher survival rates for preterm infants cared for in private institutions than in public hospitals. City hospitals reported higher estimated survival than district/provincial hospitals at all gestations except at 23-24 weeks' GA (online supplementary appendix 3).

\section{Initiating and limiting resuscitation for EPIs}

A majority of respondents reported using the American Academy of Pediatrics Neonatal Resuscitation Program (NRP) guidelines (online supplementary appendix 4). ${ }^{27}$ Fourteen hospitals reported using a local guideline developed by their department or institution. When asked about resuscitation at 23-24 weeks' GA, 14\% indicated that at their institution infants would 'always' or 'often' be resuscitated, while $66 \%$ indicated that resuscitation would 'never' or 'rarely' be initiated (figure 2). There was no significant difference between sectors, region or hospital level in the frequency of resuscitating at 23/24 weeks' gestation (online supplementary appendix 5A). At 25-26 weeks' gestation, 41\% of hospitals would 'always' resuscitate, while $21 \%$ would 'often', and 23\% would 'sometimes' resuscitate.

At 27-28 weeks' GA, 84\% of respondents indicated that they would always resuscitate (figure 2). The reported reasons for non-resuscitation in this group are listed in online supplementary appendix 5B.

Resuscitation was almost always provided at higher GAs (97\% and 99\% in the 29-30 and 31-32 weeks' GA groups, respectively).

The most frequently cited reason influencing clinicians' decision to limit resuscitation was 'respecting parents' wishes' followed by 'probability of infant death' and 'clinician's morals' (online supplementary appendix 6). 
A. $23-24$ Weeks GA

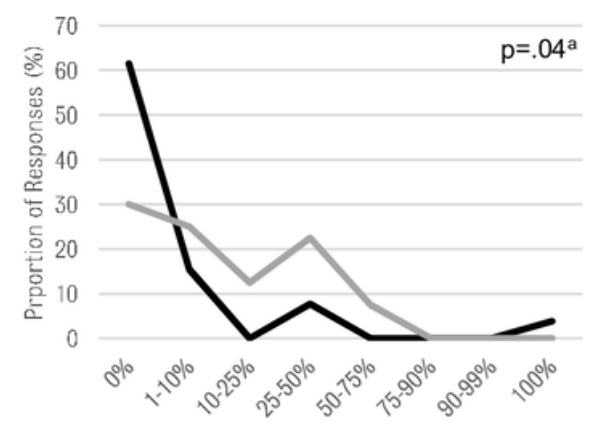

C. $27-28$ Weeks GA

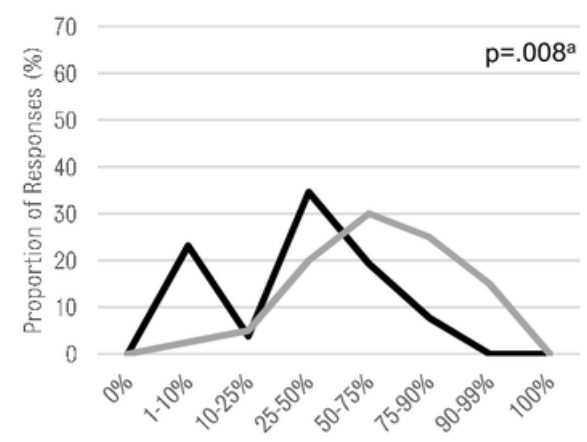

E. $31-32$ Weeks GA



B. $25-26$ Weeks GA



D. $29-30$ Weeks GA

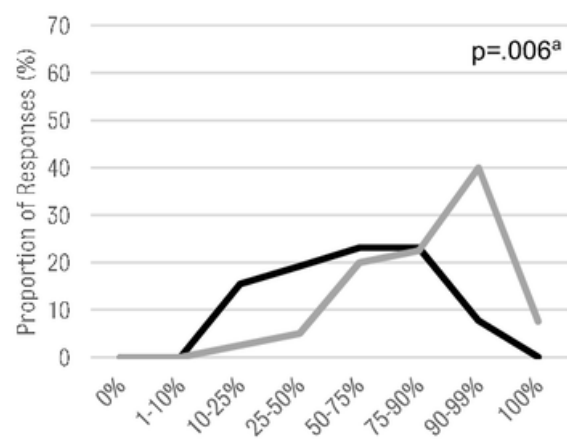

Public/Government Sector

Private Sector

Horizontal axes represent the estimated chance of survival if the infant is actively resuscitated. Vertical axes represent the proportion of responses (\%) for a given survival rate category. Total $n=65$ for hospital Levels III and IV.

${ }^{a}$ Fisher's Exact tests used to calculate $P$ values to assess for significance between private and public survival estimates in each GA category.

Figure 1 Estimated survival rates (if actively treated) at different GA categories in Level III and IV hospitals. GA, gestational age.

Most respondents reported also using birth weight as a threshold for initiating resuscitation if the GA were uncertain (online supplementary appendix 7). The median birth weight threshold reported was $500 \mathrm{~g}$ (range of 400-800 g).

No significant associations between willingness to offer resuscitation and participant characteristics were observed.

\section{DISCUSSION}

To our knowledge, this is the first study to report the availability of NICU resources and resuscitation practice for EPIs across multiple hospital sectors in an LMIC. We found large disparities between hospitals across the Philippines in the availability of NICU resources. Furthermore, we found that the financial capacity of parents influenced treatment limitation decisions and played a major role in the response to resource limitations. Our study indicated that resuscitation would generally be considered from 25 weeks' gestation in the Philippines and would usually be provided from 27 to 28 weeks' gestation, though, in the absence of national guidance, there was large variation in when resuscitation or non-resuscitation would be considered. We did not observe disparities in resuscitation practices between different types of hospitals; however, our results suggested that outcomes for EPIs may differ between sectors; respondents provided higher survival estimates for EPIs in private versus public hospitals.

\section{Resource limitations}

The number of NICU ventilators per 100 preterm births (a metric we devised for assessing resource capacity) showed striking differences between the private and public sector. The reported differences in availability of neonatal beds, ventilators and surfactant were generally consistent with the intuitive assumption that large, private, urban centres would be better resourced than small, public, rural centres, respectively. 


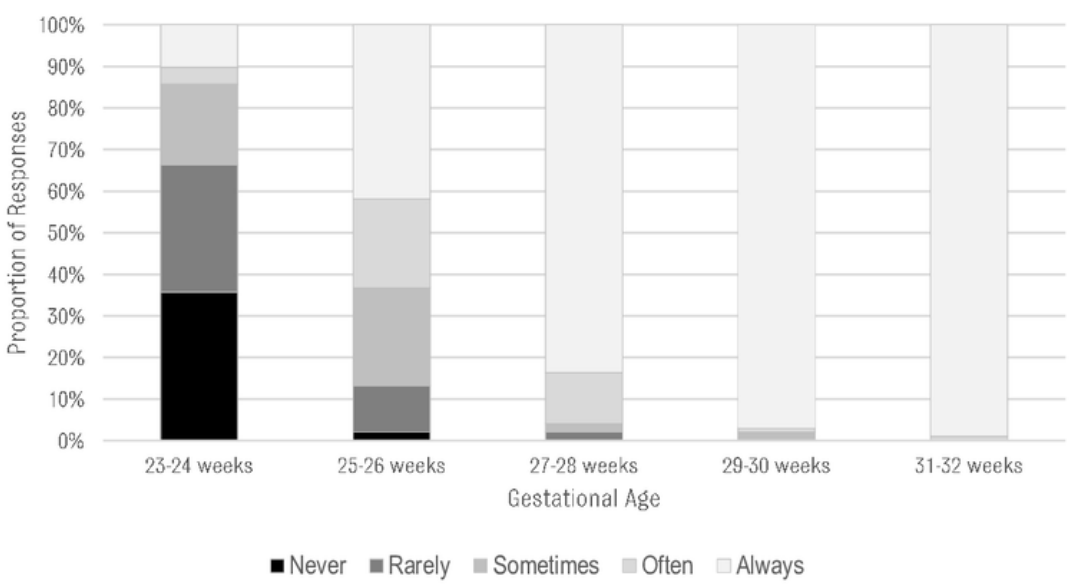

Figure 2 Frequency of initiating resuscitation for a given gestational age.

Hospitals reported wide-ranging courses of action taken in the face of resource limitations. When ventilators are at full capacity, the most commonly cited course of action was for the family to rent a ventilator, which may not be possible for poor families. It is possible that in such cases, hospitals resort to other cited responses such as hand ventilation, or attempt to identify a source of charitable funding for the family. ${ }^{28}$ Approximately one-third $(35 \%)$ of respondents cited financial capacity of the family as a limiting factor in the provision of surfactant. The reported cost of a single dose of surfactant represents approximately $9 \%$ of the average per capita annual income in the Philippines. ${ }^{19}$ For some families, incurring the costs associated with extreme prematurity may lead to financial catastrophe.

Previous studies in other LMICs have documented the financial capacity of parents as a limiting factor in resuscitation of their preterm infant. Qualitative studies from neonatal units in India have reported that families' motivations for withdrawing treatment were often based on costs, and that clinicians would only resuscitate EPIs if the family was willing to pay the entire bill themselves. ${ }^{1629}$

We found differing estimated survival rates between different hospital types. Rates were significantly lower in public hospitals compared with private hospitals for all GA bands (figure 1). Lower survival rates in public hospitals might relate to the different number and capacity of ventilators reported in our study (tables 2 and 3). Poorer outcomes might also relate to other factors, including staffing levels, experience, rates of nosocomial infection or overcrowding. ${ }^{25}{ }^{30}$ It might also conceivably relate to different risk factors in women presenting to public institutions (eg, reduced antenatal care and fetal growth restriction relating to maternal malnutrition). ${ }^{31} 32$

\section{Resuscitation}

Our survey identified that there is no single widely adopted guideline in the Philippines for resuscitation of EPIs (online supplementary appendix 4). The most commonly cited guideline, reported by 54\% of respondents, was a US guideline. The NRP 7th Edition identifies the grey zone for resuscitation between 22 and 24 weeks GA, and does not take into consideration constraints on resources. ${ }^{27}$ These guidelines may not be easily applicable to the Philippine context, and indeed, local practice seemed to differ from the NRP recommendations. In Philippine hospitals, resuscitation was generally considered to be an option from 25 weeks' gestation.
Thresholds reported in several other LMICs resemble our findings. Resuscitation is generally only considered beyond 25 weeks GA in South Africa, Lebanon and Malaysia. ${ }^{12} 1417$ In contrast, studies from elsewhere report thresholds at later GAs: 26 weeks in El Salvador, 28 weeks in India and 31 weeks in Mongolia. ${ }^{131529}$

As expected, in the absence of national guidelines, we found significant variations between institutions. Particularly at lower GA (23-26 weeks), we found a striking degree of heterogeneity, with some centres reporting that they would never or rarely resuscitate, while others reported usually or always providing resuscitation. Practice appeared more consistent for infants on reaching the 29-30 weeks' GA band. At 27-28 weeks, some centres cited parents' inability to pay as a reason to withhold treatment, while others indicated that this was based on anticipated poor outcome.

The divergence of practice seen across institutions could be due to differences in resource capacity. However, we did not observe differences in the reported rate of resuscitation between the different hospital types.

The spectrum of approaches (resuscitation offered for some infants at 23 weeks and withheld for some infants at 28 weeks) may represent a wide grey zone in which resuscitation is provided predominantly according to parental wishes. Approximately $2 / 3$ of respondents reported that 'parents' wishes' and 'financial cost (for family)' often or always affected decisions to limit resuscitation (online supplementary appendix 6). This contrasts starkly with an earlier survey of clinicians in six Pacific countries. In that study, only $26 \%$ of clinicians in Malaysia and $1 \%$ of clinicians in Japan reported 'financial cost (for family)' to often or always affect decisions to limit resuscitation. ${ }^{14}$ Of concern, our study suggested a higher prevalence of litigation fear influencing resuscitation decisions (29\%) compared with other Pacific rim countries.

\section{Limitations}

We had modest response rates, which may affect the generalisability of our results, though the proportion of private and public hospital respondents in our study was close to the nationwide ratio. We had a higher proportion of level III/IV hospitals than the nationwide distribution (approximately 25\%), yet many level I/II hospitals lack newborn care services and were not invited to participate in our study. ${ }^{23}$ 
Each hospital's response was restricted to the views of one neonatologist responding on its behalf. Respondents may have answered some questions according to their own practice, which in the absence of clear guidelines may differ from their colleagues. We relied on participant's reporting of outcomes (ie, estimated survival rate), yet such recollections or impressions of outcomes may be inaccurate or biased. We were not able to verify the accuracy of such estimates due to a general lack of evidence on outcomes for EPIs in the Philippines.

\section{CONCLUSION}

Our study provides valuable insights into the challenges of neonatal care in an LMIC. Philippine paediatricians are endeavouring to provide the same level of care that is available in developed countries; however, resource scarcity and the costs of treatment appear to be critical to decisions in a way that they are not in more well-resourced health systems. National guidelines would potentially generate greater consistency of care for preterm infants. However, they would need to reflect the context of decision making in a LMIC. The Philippine Society of Newborn Medicine is currently in the process of developing a national consensus guideline.

One challenge in establishing guidelines is the need for locally relevant data on the outcomes of treatment. The short-term and long-term outcomes of infants resuscitated at different GAs and birth weights in the Philippines would be highly useful, yet such data are currently lacking.

Finally, the perceived difference in outcome for EPIs between private and public institutions and the large out-of-pocket costs for families (a problem likely shared with other LMICs), points to the need for ethical attention to the structure and extent of funding for children's healthcare in the Philippines.

Contributors DH designed the survey, collected and analysed data, drafted the initial manuscript and reviewed and revised the manuscript. MEV-U contributed to the design of the survey and helped to evaluate, revise and edit the manuscript. MKM assisted with the collection of data and helped to evaluate, revise and edit the manuscript. DW conceived of the study, supervised and coordinated the design of the study and helped to evaluate, revise and edit the manuscript.

Funding DW was supported for this work by a grant from the Wellcome trust WT106587/Z/14/Z.

\section{Competing interests None declared.}

Patient consent for publication Not required.

Ethics approval This study was approved by the University of the Philippines Ethical Review Board (UPMREB2017-335-01) and the University of Oxford Research Ethics Committee (R51548/RE001).

Provenance and peer review Not commissioned; externally peer reviewed.

Data sharing statement All data relevant to the study are included in the article or uploaded as supplementary information.

Open access This is an open access article distributed in accordance with the Creative Commons Attribution 4.0 Unported (CC BY 4.0) license, which permits others to copy, redistribute, remix, transform and build upon this work for any purpose, provided the original work is properly cited, a link to the licence is given, and indication of whether changes were made. See: https://creativecommons.org/ licenses/by/4.0/

\section{ORCID iD}

Dean Hayden http://orcid.org/0000-0002-6554-6536

\section{REFERENCES}

1 Wilkinson D. Who should decide for critically ill neonates and how? The grey zone in neonatal treatment decisions. When doctors and parents disagree: ethics, paediatrics and the zone of parental discretion. Annandale, NSW: The Federation Press, 2016.

2 Wilkinson DJ. Gestational ageism. Arch Pediatr Adolesc Med 2012;166:567.
3 Pignotti MS, Donzelli G. Perinatal care at the threshold of viability: an international comparison of practical guidelines for the treatment of extremely preterm births. Pediatrics 2008;121:e193-e198.

4 Guillén Ú, Weiss EM, Munson D, et al. Guidelines for the Management of Extremely Premature Deliveries: A Systematic Review. Pediatrics 2015;136:343-50.

5 Nuffield Council on Bioethics. Critical care decisions in fetal and neonatal medicineethical issues. London: Nuffield Council on Bioethics, 2006.

6 Blencowe H, Cousens S, Oestergaard MZ, et al. National, regional, and worldwide estimates of preterm birth rates in the year 2010 with time trends since 1990 for selected countries: a systematic analysis and implications. Lancet 2012;379:2162-72.

7 Dimes Mof. PMNCH, Save the Children, WHO. Born Too Soon: The Global Action Report on Preterm Birth. Geneva:WHO, 2012.

8 Lee AC, Katz J, Blencowe $\mathrm{H}$, et al. National and regional estimates of term and preterm babies born small for gestational age in 138 low-income and middle-income countries in 2010. Lancet Glob Health 2013;1:e26-e36.

9 Katz J, Lee AC, Kozuki N, et al. Mortality risk in preterm and small-for-gestational-age infants in low-income and middle-income countries: a pooled country analysis. Lancet 2013;382:417-.

10 Wall SN, Lee ACC, Niermeyer S, et al. Neonatal resuscitation in low-resource settings: What, who, and how to overcome challenges to scale up? Obstet Gynecol Int J 2009; 107:S47-S64.

11 Ambrósio CR, Sanudo A, Almeida MF, MFBd A, et al. Initiation of resuscitation in the delivery room for extremely preterm infants: a profile of neonatal resuscitation instructors. Clinics 2016:71:210-

12 Charafeddine L, Ammous F, Kayle M, et al. Survival at the threshold of viability: a nationwide survey of the opinions and attitudes of physicians in a developing country. Paediatr Perinat Epidemiol 2014;28:227-34.

13 Martinez AM, Mathes ED, Foster-Rosales AF, et al. Obstetricians' attitudes and practices of life support for extremely premature low birth weight infants in El Salvador. J Neonatal Perinatal Med 2009;2:49-56.

14 Martinez AM, Partridge JC, Yu V, et al. Physician counselling practices and decisionmaking for extremely preterm infants in the Pacific Rim. J Paediatr Child Health 2005;41:209-14

15 McAdams RM, Erdenebileg A, Batra M, et al. Attitudes of healthcare providers towards non-initiation and withdrawal of neonatal resuscitation for preterm infants in Mongolia. J Health Popul Nutr 2012;30:346-52.

16 Miljeteig I, Sayeed SA, Jesani A, et al. Impact of ethics and economics on end-of-life decisions in an Indian neonatal unit. Pediatrics 2009;124:e322-e328.

17 Partridge JC, Ranchod TM, Ballot DE, et al. Intensive care for very low birthweight infants in South Africa: a survey of physician attitudes, parent counseling and resuscitation practices. J Trop Pediatr 2005;51:11-16.

18 Ambrosio CR, Sanudo A, Martinez AM, et al. Opinions of paediatricians who teach neonatal resuscitation about resuscitation practices on extremely preterm infants in the delivery room. J Med Ethics 2016;42:725-8.

19 World Bank Open Data. http://data.worldbank.org/ (Accessed 4 Oct 2018).

20 Blencowe H, Cousens S, Chou D, et al. Born too soon: the global epidemiology of 15 million preterm births. Reprod Health 2013;10:\$2.

21 Neonatal Mortality. UNICEF Data. 2018. https://data.unicef.org/topic/child-survival/ neonatal-mortality/ (Accessed 2 Aug 2018).

22 Philippine Statistics Authority, USAID. Philippines National Demographic and Health Survey 2017. Quezon City, Philippines: PSA, 2017.

23 Republic of the Philippines Department of Health. The Philippine Health System at a Glance. Manila, 2012.

24 The Constituion of the Republic of the Philippines. Article XIV, Section 7, 1987.

25 World Health Organization. The Philippines health system review. Manila: WHO Regional Office for the Western Pacific, 2011.

26 IBM Corp. IBM SPSS Statistics for Windows [computer program]. Version 25.0. Armonk, NY: IBM Corp, 2017.

27 Weiner GM, Zaichkin J. Textbook of neonatal resuscitation: American Academy of Pediatrics, 2016.

28 Lavado RF, Pantig IMT, Ulep VGT, et al. Profile of Private Hospitals in the Philippines. PIDS Discussion Paper Series, 2011.

29 Miljeteig I, Johansson KA, Sayeed SA, et al. End-of-life decisions as bedside rationing. An ethical analysis of life support restrictions in an Indian neonatal unit. J Med Ethics 2010;36:473-8.

30 Coetzee SK, Klopper HC, Ellis SM, et al. A tale of two systems--nurses practice environment, well being, perceived quality of care and patient safety in private and public hospitals in South Africa: a questionnaire survey. Int I Nurs Stud 2013;50:162-73.

31 Lawn JE, Kerber K, Enweronu-Laryea C, et al. Newborn survival in low resource settings--are we delivering? BJOG 2009;116(Suppl 1):49-59.

32 Molina HF, Nakamura K, Kizuki M, et al. Reduction in inequality in antenatal-care use and persistence of inequality in skilled birth attendance in the Philippines from 1993 to 2008. BMJ Open 2013;3:e002507.

33 Grundy J, Healy V, Gorgolon L, et al. Overview of devolution of health services in the Philippines. Rural Remote Health 2003;3:220. 